\title{
Data Mining for Assessment of Final Year Major Project (FYMP) Marks in Mechanical Engineering
}

\author{
Richa Pandey \\ Department of Mechanical Engineering, \\ Birla Institute of Technology, Mesra, \\ Ranchi- 835215
}

\begin{abstract}
Each year, a batch reaches to the completion of a final year with an essential Major project. This project is the sole basis of the assessment of the impact of all the subjects throughout their curriculum and which has led them to be called as Engineers. Engineering degree is a real time approach to many solutions which an engineer must face and solve with his skill and knowledge acquired throughout his degree curriculum. Though all the subjects are thoroughly evaluated and assessed, still to evaluate its practical approach to a problem specified is the root cause of assigning a Final year major project (FYMP). The assessment of FYMP is an important phase and a special tool has to be planned to give proper marks/ grades to the students. Many skills of the students are being judged and assessed like his way of problem framing, writing skills, presenting skills, justifying skills, analyzing skill, teamwork and overall societal impact. The relevance of the project to the current scenario and its theme and orientation also plays a vital role in assessing a student. This paper is an initiative to frame a proper rubric to do better judgment for a final year mechanical engineering major project.
\end{abstract}

Keywords: Rubrics, Final Year Major Project, Marks, Assessment, Mechanical Engineering

\section{INTRODUCTION}

All the engineering streams follow a significant rule of final year major project(FYMP) which signifies the level of attainment of the full curriculum they have studied so far. The major project means full 6 credits are assigned to it and it is carried in both the semesters of the final year, with last semester dedicated to their FYMP. Students are advised to take their projects as well as supervisors with their own choice unless and until , they are either not able to decide or do not get guide or mentors of their choice. Mechanical engineering is a vast field of many areas enculcating in it which are supposed to be called as the core of Mechanical engineering. Students are set free to take their own fields and choices. Some of the most commonly identified areas are Automobile, Refrigeration, Solar powered systems, Conventional and Non conventionalenergysources, simulation,Modeling,Analysis,CAD/CAM,Computational fluid dynamics(CFD), Vibration, Materials, Sensors and automation, Tribology, Reverse Engineering, Thermal systems, Additive manufacturing etc.

FYMP is an open platform to final year students to showcase their innovation, challenges, themes, working potential, analysis, presentation and manage. It is mostly conducted with a team mainly consisting of two and maximum four, but a selection of three group partners is said to be optimum. The main objectives of the course framed is according to the Bloom's Taxonomy to achieve excellence in FYMP ARE:

The student should be able to:

1. Identify and compose the methodology in implementing the FYMP.

2. To show a project which is inquisitive, and innovative.

3. To demonstrate the relevance of the project and its societal impact.

4. $\quad$ To find best solution and optimize the problem.

5. $\quad$ To build a team and be able to develop entrepreneurship out of it.

The students know their potential and their field of interest and reach up to the supervisors. The supervisors are no other than the teachers who have taught them directly or indirectly. Certain work is done in advance by the team of supervisors. A formal picture of the area of expertise of the supervisors is put on the website of the college and the department and a brief overview of the different areas and the supervisors is being provided, so that the students can chose the mentors properly and match their interest areas to the supervisor.

One more provision is provided to have Interdisciplinary projects approach. If any student has a flair to work under the supervision of a teacher who is not from Mechanical engineering, he may be allowed to take him as one guide and one co guide from his core department. The students are free to work in any lab with prior permission of the teacher concerned. Thus, the proper selection of a supervisor is must for any student team. A fixed amount of time is also assigned by the teacher to meet them personally from time to time and share their day to day works and status of the project. Every supervisor has his /her own way of handling the students and framing the problem. We must standardize the evaluation and assessment of the students as one single thumb rule will not solve the problem. Thus, Rubrics is the most simplified way of evaluating. Each supervisor is content to some extent as the basic outcome of the project has ben grouped in the form of rubrics and no one can blame for uneven marking standards. 
A Rubric will simplify the problem of grading and it will also be clear and visual to all. The paper will show in detail how a rubric is framed and what are the basic and essential points while framing a Rubric.

\section{OUTCOME BASED FYMP}

The grading of marks for FYMP and its outcome are the two major areas of concern. The deliverables are the major parameters for assessment. The FYMP should be able to demonstrate proper knowledge and evidence of topic chosen. This relates to the supervisor who initially checks for the project title, its objectives and how to achieve them. In FYMP, the supervisor is assigned $70 \%$ of the contribution for accountancy of the work, the project coordinator has $10 \%$, while the evaluator assigns $15 \%$ of the total evaluation. The distribution of the work is done in eight different parameters which are:

- Identification of the Problem

- $\quad$ Objective stated

- Literature Review

- $\quad$ Timeline/Gantt Chart

- Methodology adopted

- $\quad$ Product Development

- $\quad$ Thesis Writing/Journal Papers

- $\quad$ Presentation and Explanation

All the above eight areas are again then classified and clubbed for the Rubrics distribution as phase wise evaluation. Table 1 shows the marks wise grouping and the MYFP accountabilities and assessment.

Table 1

\begin{tabular}{|l|l|l|}
\hline Assessor & Accountability & Assessment in marks (\%) \\
\hline Supervisor & Project Topic & 10 \\
\hline & Project Objective & 20 \\
\hline & Attainment & 20 \\
\hline & Attendance & 10 \\
\hline & Final Thesis & 15 \\
\hline Co-Ordinator & Coordination between team & 2 \\
\hline & Meeting with Guides & 3 \\
\hline & Attendance & 2 \\
\hline & Paper/Fabrication & 3 \\
\hline Evaluator & Thesis Final Presentation & 8 \\
\hline & Work output & 5 \\
\hline & Societal impact & 2 \\
\hline
\end{tabular}

The Assessment of the students' performance as stated in Table 1 can be well placed in four important phases of FYMP given in Table 2.

Table 2 Phase to Level of Achievement

\begin{tabular}{|c|c|c|}
\hline S.No. & Phase & Level of Achievement \\
\hline \multirow[t]{4}{*}{1} & $\begin{array}{lll}\text { Project } & \text { Identification } & \text { and } \\
\text { Planning } & & \\
\end{array}$ & Topic selection \\
\hline & & Selection of Supervisor \\
\hline & & $\begin{array}{l}\text { Selection } \\
\text { Tools/hardware/software }\end{array}$ \\
\hline & & $\begin{array}{l}\text { Distribution of Work / Gantt } \\
\text { chart }\end{array}$ \\
\hline \multirow[t]{4}{*}{2} & $\begin{array}{l}\text { Feasibility, Objectives and } \\
\text { Methodology }\end{array}$ & Outlining the objective \\
\hline & & Literature Review \\
\hline & & Witing the Basic Methodology \\
\hline & & $\begin{array}{l}\text { Checking the Feasibility if /buts } \\
\text { and hows }\end{array}$ \\
\hline \multirow[t]{6}{*}{3} & $\begin{array}{l}\text { Project Implementation and } \\
\text { Outcome }\end{array}$ & Skill development \\
\hline & & Workshops \\
\hline & & Paper writing \\
\hline & & Fabrication \\
\hline & & Testing \\
\hline & & Application \\
\hline \multirow[t]{4}{*}{4} & $\begin{array}{l}\text { ProjectPost Demonstration } \\
\text { /Presntation/Thesis }\end{array}$ & Project presentation \\
\hline & & Project thesis writing \\
\hline & & Project outcome to society \\
\hline & & Workable project \\
\hline
\end{tabular}


The assessment of the student performance is set up according to a defined point. Table 3 shows the segregation and allotment of the marks for FYMP. The whole process starts with a dedicated network of events linked together one by one starting with the selection of the proposal and the selection of guide. Now, it is the work of the Guide/ supervisor to properly investigate the selected topic and help the students in final binding of the objectives and the topic assigned to FYMP. The objectives once outlined require a proper Gantt chart which will interrelate the sequential approach of the work and the attainment of the goal specified. If the proposal ends up to a fabricated Model, a costing research also has to be conducted beforehand so that it does not become a burden to the students. After doing this initial homework, a proper and deep literature review has to be done which is a requirement too. This will lead up to the list of references as well as a guide to the students to formulate their work approach properly and effectively.

The work of the coordinator of the project is to properly investigate the procedure followed by the students and make them to be tuned from time to time. Their duty relies on their effective guidelines and coordination between the students and their mentors which sometimes is stressed due to certain unavoidable conditions. After literature Survey, the work process is started with the methodology adopted and stated in the time chart.A mid term evaluation of the work FYMP, is an essential means of evaluating the progress of the students . The output of the project at last, will be demonstrated by a presentation and an external evaluator is invited to evaluate and judge as per table 4 constraints. The dissertation / thesis is a way to properly present their work through content and references as compiled. The assessment criteria of the project report is also shown in table 5. Table 6 lists the project output evaluation themes. The supervisors' marks are also evaluated as per the guidelines given in table 7 . The dissertation is an important parameter and carries marks for the FYMP as given in table 8. The demonstration and the presentation as given in Table 9 also have their criteria of judgement and grading.

\section{$2 \quad$ RESULTS AND DISCUSSIONS}

\begin{tabular}{|c|c|}
\hline Equivalent Stress (Max) [Pa] & Equivalent Elastic Strain (Max) [m/m] \\
\hline 1269.5 & $5.3177 \mathrm{e}-007$ \\
\hline 2539.1 & $1.0635 \mathrm{e}-006$ \\
\hline 3808.6 & $1.5953 \mathrm{e}-006$ \\
\hline 5078.2 & $2.1271 \mathrm{e}-006$ \\
\hline 6347.7 & $2.6589 \mathrm{e}-006$ \\
\hline 7617.3 & $3.1906 \mathrm{e}-006$ \\
\hline 8886.8 & $3.7224 \mathrm{e}-006$ \\
\hline 10156 & $4.2542 \mathrm{e}-006$ \\
\hline
\end{tabular}

Posterior Leaf Spring AFO: In this model, the critical section was identified at the retromalleolar region next to the ankle trim line with a maximum stress of $10156 \mathrm{~Pa}$ with a considerable factor of safety. The maximum strain and deformation were also observed in the same region as shown in the figure and were observed to be within safe limits. The considerably low values of deflection and strain point out the lack of flexibility in this model.

Table 2: Stress-Strain Values for Design 2

\begin{tabular}{c|c} 
Equivalent Stress (Max) $[\mathbf{P a}]$ & Equivalent Elastic Strain $(\mathbf{M a x})[\mathbf{m} / \mathbf{m}]$ \\
\hline $2.1195 \mathrm{e}+007$ & $1.6122 \mathrm{e}-003$ \\
$4.239 \mathrm{e}+007$ & $3.2242 \mathrm{e}-003$ \\
$6.3584 \mathrm{e}+007$ & $4.836 \mathrm{e}-003$ \\
$8.4778 \mathrm{e}+007$ & $6.4477 \mathrm{e}-003$ \\
$1.0597 \mathrm{e}+008$ & $8.0592 \mathrm{e}-003$ \\
$1.2717 \mathrm{e}+008$ & $9.6705 \mathrm{e}-003$ \\
$1.4836 \mathrm{e}+008$ & $1.1282 \mathrm{e}-002$ \\
$1.6955 \mathrm{e}+008$ & $1.2893 \mathrm{e}-002$
\end{tabular}

Future Work

\section{REFERENCES}

[1] M. Walbran, K. Turner, and A. J. McDaid: Customized 3D printed ankle-foot orthosis with adaptable carbon fibre composite spring joint. Cogent Engineering (2016)

[2] Chengbo Yin: Gait cycle analysis and mechanical design of ankle foot orthosistestbed. (2015)

[3] G. Gomes, I. Lourenco, J. Oliveira, M. Gomes, A. Vale, L. Freire, P. Quental, H. Policarpo, and J. Matos. Structural reinforcements on AFO's: A study using computeraided design and finite element method. ENBENG 2017 - 5th Portuguese Meeting on Bioengineering, Proceedingsv(2017)

[4] Upendra Kumar: Lower Limb Orthosis. Bedside Clinics in Orthopedics (WardRound and Tables), pages $205205,2017$.

[5] Harish Kumar Banga, Parveen Kalra, R M Belokar, and Rajesh Kumar: Development of Ankle Foot Orthoses ( AFO ) to enhance walking and balance on Foot Drop Patients in India by Additive Manufacturing. Proceedings 19th Triennial Congress of the IEA (2015) 